\title{
GIENCIA Y ENSEÑANZA EN LA ESPAÑA DEL MIL SETECIENTOS
}

\author{
Manuel A. SELLÉS \\ Dpto. de Logica. UNED
}

$\mathrm{Al}$ abrirse el siglo de las luces, la estructura docente española todavía seguía respondiendo a las antiguas necesidades feudales. Las enseñanzas de primeras letras se hallaban poco extendidas, sobre todo entre la abrumadora mayoría campesina de la población. No existía nada parecido a lo que más tarde se llamarían enseñanzas medias - tampoco se había desarrollado una clase mediaa no ser que se califiquen de tales los estudios de latinidad y filosofía de los seminarios eclesiásticos y la Facultad menor de Artes de las universidades. Y éstas, las universidades, dominaban en solitario la enseñanza de nivel superior, manteniendo el modelo tradicional: formaban teólogos para la Iglesia, juristas para el aparato burocrático del Estado, y médicos.

Un siglo más tarde resultaría ya difícil cuantificar las instituciones docentes que, al margen de la universidad, impartían a uno u otro nivel saberes de índole científica. Habían sido creadas porque la reestructuración y modernización del país acometida por los primeros Borbones demandaba, ente otras cosas, la formación de técnicos y profesionales cualificados. Para lograr este objetivo, al margen de ocuparse de la reforma de las universidades, se estableció un buen número de nuevos centros de enseñanza.

El desarrollo de esta estructura docente respondió más a la búsqueda urgente de soluciones que a una planificación meticulosa, sendo consecuentes sus circunstancias con los vaivenes políticos. Muchos proyectos, significativamente el establecimiento de una Academia nacional de Ciencias, fueron pospuestos por falta de medios y de interés, y una buena porción de los que se llevaron a la práctica nacieron generados por necesidades más o menos acuciantes. En 
general, el procedimiento seguido fue la centralización, la modernización y, en una segunda etapa, la racionalización y la uniformización. Por centralización hay que entender que las nuevas instituciones surgieron dependiendo directamente del Estado, y que tal dependencia se buscó con la reforma de las ya existentes, notablemente las universidades. La modernización supuso una apuesta decidida por las utilidades de las nuevas ciencias en unos procesos de aprendizaje que hasta el momento, en la mayoría de los casos, habían dependido de la mera transmisión de conocimientos empíricos. La subsiguiente demanda de ciencia y tecnología, que el país no podía satisfacer, movilizó a su vez una política de introducción de novedades desde el extranjero por las vías del envío de pensionados, la contratación de científicos y técnicos foráneos, y la adquisición literalmente masiva de libros e instrumentos.

Las necesidades y proyectos surgidos de la administración estatal a lo largo de este proceso coincidieron, en algunas ocasiones, con las demandas económicas y sociales; en otras, sin embargo, se tuvo que vencer la obstrucción de grupos que veían perjudicados sus intereses o que, simplemente, no creían en la utilidad de los cambios proyectados. También, por otra parte, los distintos elementos implicados en el proceso difirieron, en ocasiones sensiblemente, en la apreciación del alcance y utilidades de los nuevos saberes y en su ubicación institucional idónea. Del pulso entre todas estas instancias, cuya consideración difícilmente cabría en estas páginas, resultará la configuración que la enseñanza de las ciencias asumió en el siglo de las luces ${ }^{1}$.

Cronológicamente, y a grandes rasgos, se pueden distinguir tres etapas en el desarrollo de las instituciones docentes. En general, hasta la expulsión de la Companía de Jesús en 1767, este desarrollo se limitará casi exclusivamente a la fundación y consolidación de las academias militares, una de las primeras urgencias del momento. En una segunda etapa, que podría extenderse hasta finales de la década de los ochenta, se abre un gran programa ilustrado en el terreno de la educación en general y de la ensefíanza de las ciencias en particular. Son los años en que algunos de los estamentos civiles de la población comienzan a contar con centros de docencia que les servirán de trampolín para el desarrollo de su profe-

I Todavia la mejor imagen global - ya que no la más actualizada- del movimiento ilustrado español sigue siendo la presentada por J. SARRAIlH, La España ilustrada de la segunda mitad del siglo XVIII, México: Fondo de Cultura Económica, 1957 (La ed. en francés, 1954). 
sionalización, como será el caso de los cirujanos o los pilotos. También se abrirán escuelas con el objetivo de desarrollar la agricultura y la industria y optimizar la ensenanza de algunas profesiones mecánicas, aspectos en los que colaborarán las Sociedades Económicas de Amigos del País. En una última etapa, abierta con los últimos ańos del siglo y acotada por la Guerra de la Independencia, comenzará a desarrollarse un nuevo proceso de institucionalización tendente a sustituír desde la sociedad civil todas aquellas funciones ajenas a su instituto que la milicia, a falta de otros recursos, había tenido que asumir desde la primera parte del siglo. Se trata de un proceso abordado desde el Estado, pero que comenzará a abrirse a las necesidades de una incipiente burguesía cada vez más consciente de las utilidades del saber para la consecución de sus propios fines ${ }^{2}$.

Aquí he optado, sin embargo, por una presentación temática, basada en la consideración, inevitablemente superficial, del desarrollo de la enseñanza de las ciencias en algunas áreas destacadas: la educación nobiliaria, la reforma de la universidad, las profesiones sanitarias y militares y algunos aspectos del desarrollo de las profesiones técnicas serán las cuestiones que, sin olvidar los planteamientos anteriores, parte todos ellos del complejo tejido de la historia, trataré de esbozar en las páginas que siguen ${ }^{3}$.

\section{El Colegio Imperial y los Seminarios de Nobles}

El Colegio Imperial fue fundado en 1625, y puesto a cargo de la Compañía de Jesús. Era una institución destinada al ornato de la Corte y a la educación de los primogénitos de la nobleza. Contaba con diecisiete cátedras, y entre ellas las había dedicadas a las matemáticas, la filosofia natural, y la historia natural. Sin embargo, no parece que, en general, las enseñanzas científicas fuesen allí muy destacadas, salvando las actividades del P. Zaragoza ${ }^{4}$. En el siglo XVIII

2 Esta periodización concuerda razonablemente con la propuesta por A. LAFUENTE y J. L. PESET en "Las actividades e instituciones cientificas de la España ilustrada», en M. SELLES, J. L. PeSET y A. LAFUENTE, Carlos III y la ciencia de la Ilustración, Madrid: Alianza, 1988, págs. 29-79.

3 Si bien la exposición se atendrá particularmente a los desarrollos metropolitanos.

4 Véase H. CAPEL, "La geografía como ciencia matemática mixta. La aportación del círculo jesuítico madrilefio en el siglo XVII", Geocritica. Cuadernos críticos de Geografía Humana, n. 30. Univ.de Barcelona, 1976. Sobre la situación de las actividades científicas en la España del seiscientos, véase J.M. LOPEZ PIÑERO, Ciencia y técnica en la sociedad española de los siglos XVI y XVII, Barcelona: Labor, 1979. Será asimismo de utilidad la consulta de Estudios sobre la 
sus enseñanzas entraron en franca decadencia; en 1761 sólo se enseñaba gramática latina y teología moral 5 . Tras la expulsión abrió de nuevo sus puertas con el nombre de Reales Estudios de San Isidro y unas enseñanzas renovadas, entre las que se contaban las matemáticas y la física experimental. Para ello se contrató como instrumentistas a los hermanos Rostriaga, artesanos de reconocida habilidad, y el catedrático de la disciplina, Fernández Solano, adquirió un buen conjunto de instrumentos en el extranjero ${ }^{6}$.

Al margen del Colegio Imperial, existían los llamados Seminarios de Nobles, asimismo a cargo de los jesuítas. Al iniciarse el siglo los habia ya en Barcelona y en Valencia; el de Madrid se fundó en 1725, con el propósito elitista de acoger a los nobles que asistían al Colegio Imperial, el cual a lo largo de la centuria anterior se hab́a visto cada vez más frecuentado por los vástagos de la burguesía madrileña. En el momento de su expulsión había 112 de estas instituciones en la península y 120 en territorio americano ${ }^{7}$. Las materias que se impartían en el Seminario de Madrid eran las primeras letras, latinidad, poética y retórica, filosofía moral, matemáticas, francés, geografía e historia, música, baile, esgrima y equitación. Las ciencias no se contaban entre aquellos conocimientos que servían de ornato a esta clase nobiliaria, para la que se buscaba una cultura de corte humanista ${ }^{8}$. Tras la expulsión, el Seminario de Madrid quedó en manos del Estado, y se renovaron sus enseñanzas, introduciéndose el estudio serio de las matemáticas y de la física experimental ?

ciencia española del siglo XVII (ed. Asociación Nacional de Historiadores de la Ciencias Española), Madrid, 1935.

5 El proyecto de la Compafía era establecer un centro de enseñanza superior puesto bajo su control y que incluyese, entre otras materias, también los estudios náuticos, hidrográficos y geográficos, al igual que los obruvieran y desarrollaran en Francia. Hasta la expulsión, en 1767, el cargo de Cosmógrafo Mayor de Indias recaería, efectivamente, en un catedrático de matemáticas del Colegio. El detallado estudio de J. SimON DIAZ, Historia del Colegio Imperial de Madrid, 2 vols., Madrid, 1952-59, recoge algunas noticias de interés.

6 Véase V. GUIJARRo MORA, Los instrumentos de la fisica ilustrada. Física experimental en Los Reales Estudios de San Isidro de Madrid (1770-1835), Tesis doctoral, Madrid: UNED, 1996.

7 F. Aguilar PINAL, "La política docenten, en Historia de España Ramón Menéndez Pidal, vol.31: La Época de la Ilustración. El Estado y la cultura (1759-1808), Madrid: Espasa-Calpe, 1987, págs.437-484; en pág.454.

8 Véase F .AGUILAR PINAL, «Los reales Seminarios de Nobles en la política ilustrada espanolan, Cuadernos Hispanoamericanos, n. 356 (febrero 1980), págs.329-349.

9 El plan de estudios sería redactado por un militar, Antonio Angosto, director de la institución, en 1785. En matemáticas se estudiaría aritmética, geometría, trigonometría, álgebra, mecánica, perspectiva, arquitectura, fortificación, artillería, astronomía, "y demás partes 
También se perdió el carácter elitista, al incorporarse a la institución en 1790 los cadetes de la Escuela Militar de Ocaña y los alumnos de la Escuela de Pajes de la Corte. De todos modos, acabó por entrar en una etapa de decadencia.

Otro modelo de Seminario, nacido ya con carácter netamente ilustrado, fue el establecido en Vergara. Fue fundado por la Sociedad Vascongada de Amigos del Pás, e inició su andadura en 1776 con el nombre de Real Seminario Patriótico. Su plan de estudios comprendía una primera etapa de "ensefianza general", con el estudio de las primeras letras, latín y lenguas modernas, humanidades, nociones de física experimental e historia natural, matemáticas, dibujo, baile, música, esgrima y equitación. En una segunda etapa, se buscaba impartir enseñanzas modernas que no pudiesen seguirse en otras instituciones, como la universidad o las academias militares. Estas consistirian en comercio, química, mineralogia, metalurgia, arquitectura pública, agricultura y agrimensura, y economía política ${ }^{10}$. En el ramo de química y mineralogía destacó señaladamente; pero éstas fueron las únicas enseñanzas especializadas que la institución pudo llegar a impartir ${ }^{11}$.

En 1785 Campomanes, fiscal del Consejo de Castilla, propuso cubrir el vacío dejado por la expulsión de los jesuitas con la fundación de distintos seminarios de nobles repartidos por la geografía española, con planes de estudio análogos a los impartidos en Vergara y Madrid. Se interrogó a las Sociedades Económicas de Amigos del País sobre la posible ubicación de estas instituciones y la procedencia de los fondos para sostenerlos. Sin embargo, los edificios de los antiguos colegios de la Companía de Jesús habían sido ya destinados a otros fines, y la financiación se mostraba como un asunto espinoso; de modo

matemáticas", durante cuatro años. Y esto serviria de introducción a la física experimental. Este plan seguiría vigente hasta 1799 , pero no hay indicios de que pasase del terreno de los proyectos. Véase J. Simón DIAZ, Historia..., op.cit., vol.2, págs. 179-184. Sobre esta etapa de la institución, J.L. PESET, "Ciencia, nobleza y ejército en el Seminario de Nobles de Madrid (1770-1788)", en Maydns y la Ilustración, Simposio Internacional en el Bicentenario de la muerte de Gregorio Mayáns. Oliva, 1982, págs. 519-535.

10 En la primera etapa, las humanidades abarcaban la mitología, retórica, lógica, geografia, historia, blasón y filosoffa moral; dentro de las matemáticas se estudiaba álgebra, geometría, esfera y cronología; además también se impartían elementos de agricultura. Véase M.T. ReCARTE BARRIOLA, Ilustración vasca y renovación educativa: la Real Sociedad Bascongada de los Amigos del Pats, Salamanca: Univ.Pontificia, 1990, págs. 156 ss.

11 Véase L. SilvaN, Los estudios cientificos en Vergara a fines del siglo XVIII, San Sebastián, 1953, reeditada junto con El quimico Luis José Proust, 1754-1826, Donostia-San Sebastián: Real Sociedad Bascongada de los Amigos del País, 1992. 
que nada se consiguió. El plan de estudios que debra aplicarse uniformemente en todos ellos se elaboró en 1788 , y en él las ciencias no desempeńaban un papel demasiado destacado; geometría, aritmética y física experimental serían las únicas materias introducidas. Una novedad consistía en la admisión en ellos de los vástagos de la burguesía, al igual que se hacía en Vergara ${ }^{12}$.

\section{Las reformas universitarias}

Tras la expulsión de los jesuítas, el gobierno de Carlos III acometió la reforma universitaria. Habla una treintena de universidades repartida por la geografía peninsular y, contando con las creadas en el siglo XVIII, otras once en territorio americano. Su estructura docente general consistía en una facultad llamada "menor", la denominada de Filosoffa o Artes, la cual daba paso a las facultades "mayores" de Teología, Cánones, Derecho y Medicina. Hasta el reinado de Carlos III, en que se abordó su renovación, las universidades españolas siguieron fieles a los métodos y planes de estudio tradicionales. En las facultades de Artes se estudiaba fundamentalmente a Aristóteles; en las de Medicina, a Galeno y a Hipócrates. El método seguía siendo el de la disputa escolástica. Pero no sólo las materias estaban anticuadas. Las facultades de Teología dominaban la institución y la desgarraban entre encarnizadas disputas de escuela. Por otra parte, el absentismo y los abusos en la concesión de grados habian llegado a límites intolerables. Las reformas se abordaron buscando el sometimiento de las universidades y colegios mayores a la autoridad real y la imposición de planes de estudios más modernos ${ }^{13}$.

El espacio que podían ocupar los nuevos saberes dentro de la universidad se situaba en las Facultades de Artes y de Medicina. Un modesto primer paso hacia la modernización de los conocimientos médicos se dio en 1733 , cuando se dictaron nuevas constituciones para la universidad de Valencia como consecuencia de la abolición de los fueros y privilegios de este Reino tras la victoria de Felipe V en la Guerra de Sucesión. Aunque las aspiraciones de un grupo de

12 Véase F. AgUilar PiNAL, "Los reales seminarios...", op.cit., págs.11 ss.

13 Sobre la situación general y reformas en la universidad, véase M.y J.L. PESET, La universidad española (siglos XVIII y XIX). Despotismo ilustrado y revolución liberal, Madrid: Taurus, 1974. También A. ALVAREZ DE MORALES, La Ilustración y la reforma de la universidad en la España del siglo XVIII, Madrid, 1971. 
profesores de desterrar a Galeno y sustituírlo por autores modernos como Boerhaave, Haller o Hoffman no fueron atendidas, se permitió que la doctrina de estos autores pudiese impartirse en las clases. Las enseñanzas de matemáticas no tuvieron esa suerte, repitiéndose las disposiciones para su docencia que se habian dictado en $1611^{14}$.

Las reformas comenzaron tras la expulsión de los jesuítas. Un primer paso consistió en solicitar al erudito valenciano Gregorio Mayáns un nuevo plan de estudios, que elaboró en 1767; se trataba de un plan bastante renovador para la Facultad de Medicina, que inclúa el estudio de los autores modernos y la atención a las disecciones anatómicas ${ }^{15}$. No se llevó a la práctica, al optarse por solicitar a las mismas universidades la configuración de planes de estudio específicos. El que presentó la universidad de Salamanca inclúa pocas novedades. A lo más que se llegó en esta universidad, forzada por el Consejo de Castilla, fue a introducir en la Facultad de Artes estudios de aritmética, geometría, álgebra y física experimental para los futuros médicos, reservando para los teólogos la física aristotélica. Dentro de la Facultad de Medicina se introdujo a Boerhaave, se buscó mejorar las enseñanzas anatómicas y se propuso la fundación de un jardín botánico; pero se desoyeron las recomendaciones del médico de Leiden acerca de la necesidad del estudio previo de las nuevas ciencias y de la clínica, la obtención directa de conocimiento a la cabecera del enfermo ${ }^{16}$.

14 Se indicaba que se leerá ula tercera parte de la Matemática, que es la Astronomía, la Cosmografía, la Geografia, Hidrografía, la fábrica y uso del astrolabio y de discriptione horologium solarium, las teóricas de los planetas, con la explicación de las tablas astronómicas del Señor Rey Don Alfonso el Sabio; y alli tratará del modo de computar los novilunios, plenilunios, eclipses y las conjunciones, oposiciones y aspectos de los demás planetas, todo lo cual se comprende en el Almagesto de Ptolomeo." Véase M. y J. L. PESET, "Felipe V y la Universidad de Valencia. Las Constituciones de 1733", en Primer Congreso de Historia del País Valenciano, 3 vols., Valencia, 1973-76, vol. 3, págs. 597-607; la cita, en pág. 605.

15 A nivel global, el plan no es excesivamente avanzado. Quizás la novedad más importante, desde el punto de vista de las enseñanzas cientificas, es la introducción de las matemáticas en un plano utilitario, constituyendo un estudio independiente que podrían seguir "los oficiales de las artes mecánicas y los marineros y aplicados a la mercancían; la filosofia, en cambio, "puede enseñarse sin cálculos matemáticos». (Recuérdese que el estudio de la física se inclúa dentro de aquélla). Véase M.y J.L. PESET, Gregorio Mayáns y la reforma universitaria, Valencia: Ayuntamiento de Oliva, 1975.

16 La apuesta por la tradición de la mayoría conservadora es clara; los miembros del claustro informan que "no nos podemos apartar del sistema del Peripatom, pues «los [principios] de los modernos filósofos no son a propósito para conseguir los fines que se intentan por medio de este estudion. Los de Newton, "si bien disponen al sujeto para sr un perfecto matemático, nada 
Otras universidades, Sevilla, Granada y Valencia, presentaron planes modernos. El primero fue elaborado por Pablo de Olavide en 1769, y en él se proponía la inclusión del estudio de la aritmética y la geometría dentro de la lógica, seguida por el estudio de la física, que englobaría la metafísica; el plan preveía también el establecimiento de una Facultad de Matemáticas. Para la Medicina, el plan era completo: anatomía, patologia, química, botánica, farmacia y clínica ${ }^{17}$. La universidad de Granada siguió estos pasos en 1776, introduciendo además la novedad de incorporar la enseñanza de la cirugía. La universidad de Valencia, en fin, de manos de su rector Vicente Blasco, iba a recibir también un moderno plan de estudios en 1786. Se renovó la Facultad de Artes y se establecieron cuatro cátedras de matemáticas, si bien no obligatorias; dos de ellas llevaban el título de mecánica y física experimental y de astronomía ${ }^{18}$. Y los nuevos estudios de medicina incluían, como ya propusiera Olavide, ensenanzas de química, botánica y farmacia ${ }^{19}$.

ensefian para que sea un buen lógico y metafísicon; los de Gassendi y Descartes "no simbolizan tanto las verdades reveladas, como los de Aristóteles". Afirman, por último, que «no vemos en sus sistemas que se establezcca método que descubra mayores utilidades y adelantamientos en las ciencias". Citado en M. y J.L. PESET, La universidad española..., op.cit., pág.218. Sobre esta universidad, G.M. ADDY, The enlightenment in the University of Salamanca, Durham: Duke Univ., 1966, M. y J.L.Peset, El reformismo de Carlos III y la Universidad de Salamanca, Salamanca, 1969; J.L. y M.Peset, Carlos $I V$ y la Universidad de Salamanca, Madrid: CSIC, 1983; J. L. Peset, "Los caminos de la ciencia. 2. El siglo XVIII", en M. Fernández Álvarez et al (eds.), La Universidad de Salamanca. II. Docencia e investigación, Universidad de Salamanca, 1990, págs. 137-149.

17 Sobre el plan de Olavide, F .AguILAR PIÑal, La Universidad de Sevilla en el siglo XVIII. Estudios sobre la primera reforma universitaria moderna, Sevilla, 1969.

18 Los textos básicos serán las Lecciones matemáticas de Lacaille y la primera parte del Examen Maritimo de Jorge Juan. Dentro de la mecánica y física experimental se impartiría estática, dinámica, hidrostática, hidrodinámica, b́ptica, catóptrica, dióptrica y perspectiva, junto a la explicación de máquinas y experiencias conducentes a udar a conocer las propiedades de los cuerpos sólidos y fluidos, especialmente del aire, del agua, del fuego y de la luz». Véase A.E. TEN, «El Plan de Estudios del rector Blasco y la renovación científica en la universidad española de fines del siglo XVIII", en Plan de estudios aprobado por S.M. y mandado observar en la Universidad de Valencia, Valencia: Ayuntamiento de Valencia, 1984, págs.91-106.

19 Véase J.L. PESET, «Los estudios de Medicina», en ibid., págs. 65-76. Más extensamente, «Reforma de los estudios médicos en la Universidad de Valencia. El Plan de Estudios del rector Blasco en 1786m, Cuadernos de Historia de la Medicina Española, 12 (1973), págs.213-264, y "Ciencia y clínica en las aulas médicas", en M. Peset (coord.), Historia de la Universidad de valencia II. La Universidad ilustrada, Valencia, Univ. De Valencia, 2000, págs. 221-237. También R. Gago et al, «El plan de estudios del Rector Blasco (1786) y la renovación de las disciplinas cientificas en la Universidad de Valencia: La química y la enseñanza clínican, Estudis, 6 (1977), págs. 157-169. 
Era ya, sin embargo, un tanto tarde para emprender todas estas reformas. El temor suscitado por la Revolución Francesa, quizás también el cambio de monarca, dejaron sin apoyo a una reforma que tratará sin éxito de seguir su camino en solitario. En 1787, médicos y filósofos, que tradicionalmente ocupaban los últimos lugares en asientos, voz y voto, reivindicarán sus derechos frente al claustro de la universidad de Salamanca y presentarán poco después nuevos planes de estudio. Los médicos señalan los defectos del plan del 71 y buscan, siguiendo el modelo valenciano, reforzar la presencia de las ciencias básicas y de la enseñanza clínica; también tratan de estrechar el vínculo con la cirugia. Pero nada se consigue ${ }^{20}$.

De hecho, las reformas universitarias nunca llegan a aplicarse en toda su extensión. En Granada no se logra inaugurar un teatro anatómico hasta 1794, mientras que la enseñanza de la clínica médica queda sólo en el papel ${ }^{21}$. En Valencia esta materia tuvo mejor suerte, pero de todos modos las reformas se aplicaron con dificultad ${ }^{22}$. Por su parte, la enseñanza de la astronomía languideció por la escasez de alumnos, quedando sin erigir el observatorio que se había proyectado ${ }^{23}$. La andadura de la física experimental fue, aunque discreta, más regular, pero careció de evolución ${ }^{24}$. En cuanto al laboratorio de química, nunca llegó a establecerse de forma definitiva, pero a partir de 1791 funcionó con continuidad un establecimiento provisional ${ }^{25}$.

20 J.L. y M. PESET, Carlos $I$..., op.cit., págs. 78 ss.

21 J.L. PESET, "La Facultad de Medicina de Granada...», op.cit., pág. 205.

22 Sobre su andadura, J. Navarro, "La introducción de la medicina clínica en España. La Cátedra de Medicina Práctica de la Universidad de Valencian, Asclepio, 41(2) (1989), págs. 157175.

23 A.E. TEN, "Los comienzos de la astronomía institucionalizada en la Universidad de Valencia. La enseñanza tras el Plan Blasco: 1787-1807", en M.Hormigón (ed), Actas del II Congreso de la Sociedad Española de Historia de las Ciencias, 3 vols., Zaragoza, 1984, vol.3, págs. 369-382. Asimismo «La construcción de un observatorio astronómico a finales del XVIII. La polémica sobre las características del observatorio de Valencia», en Actas Simposium 250 aniversario del nacimiento de J. C. Mutis, Cádiz, 1982. También «El primer observatorio astronómico universitario en la España moderna", Estudi, febrero 1984, págs. 20-22.

24 Véase A.E. TEN, "La Física en la Universidad española de fines del siglo XVIII y principios del XIX. La Universidad de Valencia y su Aula de Mecánica y Física Experimental", Llull, 6 (1983), págs. 165-189.

25 A.E. TEN, «Un intento de renovación cientifica en la universidad del siglo XVIII. La cátedra de química de la Universidad de Valencia", Llull, 5 (1983), págs. 133-147. También "La ciencia experimental en la universidad espanola de la Ilustración. El laboratorio químico de la Universidad de Valencia: 1787-1807", Asclepio, 37 (1985), págs. 287-320. 
La universidad, estructurada para formar teólogos, juristas y, casi como mal menor, médicos, no era la vía por donde podía desarrollarse la ciencia moderna, y las reformas no podían aspirar más que a una más o menos modesta actualización de saberes. Estas reformas no afectaron a la estructura global de la institución, sino sólo a la creación de algunas cátedras, destinadas a nuevas áreas del saber. La medicina, como técnica, y la filosofía, en su vertiente natural, contendían con una realidad que no tenía cabida entre los objetivos de los saberes universitarios tradicionales.

\section{Las profesiones sanitarias}

$\mathrm{Al}$ acceder al trono español, los Borbones encontraron una estructura sanitaria bien consolidada a través del antiguo Tribunal del Protomedicato. Esta institución encabezada por tres Protomédicos, cuyo origen se remonta a los Reyes Católicos, había surgido por la necesidad de uniformar los certificados expedidos por las distintas universidades para la práctica de la medicina, así como para controlar la capacitación de aquellos profesionales de la sanidad que no habían pasado por ellas. Sin embargo, su autoridad, que se extendía a todo el Reino de Castilla, sólo podía ejercerse directamente hasta cinco leguas de la Corte, teniendo que solicitar permiso del Consejo de Castilla para actuar más allá de este límite. Esta situación favorecía de hecho el intrusismo dentro de la práctica sanitaria. Por otro lado, en las regiones forales la organización era distinta, reasidiendo en general el control profesional en manos de gremios y cofradías. La política seguida por la corona, en busca de la centralización y el control, fue situar a médicos de confianza en dicho Tribunal, y ampliar sus competencias $^{26}$.

Este poder médico tradicional ejercido a través del Protomedicato, que contaba entre sus competencias con la de examinar a cirujanos y farmacéuticos, se verá cuestionado a lo largo del siglo por estos profesionales ${ }^{27}$. En una

26 Véase sobre todo esto M.C. CALlEJa FOlguERA, La reforma sanitaria en la España ilustrada, Madrid: Universidad Complutense, 1988.

27 El proceso se estudia en A. Lafuente, J. Puerto Sarmiento y M.C. Calleja FOLGUERA, "Los profesionales de la sanidad tras su identidad en la Ilustración española", en J.M. SANCHEZ RON (ed), Ciencia y sociedad en España: de la Ilustración a la Guerra Civil, Madrid: Eds.El Arquero/CSIC, 1988, págs. 71-92. 
decidida apuesta por la modernidad, los cirujanos trataron de emanciparse de esta tutela y de elevar su profesión a un rango equiparable con la medicina, llegando a absorber a ésta.

$\mathrm{Al}$ abrirse el siglo, la cirugía era una disciplina poco prestigiada. Frente a los cinco años de estudios universitarios y dos de prácticas que se le exigían a un médico para ejercer su profesión, a un cirujano latino sólo se le exigía haber asistido durante un año a los cursos de la Facultad de Artes, y tres a los de Medicina. A un cirujano romancista, por su parte, sólo se le exigían cinco años de práctica. Se comprende que escaseasen los primeros, pues quien podía asistir a la universidad optaba por cursar medicina, y que la impericia de los segundos, limitados a la aplicación de unas pocas técnicas, hubiese desacreditado totalmente la profesión. En un escalón todavía inferior se hallaban los cirujanos barberos ${ }^{28}$.

Cuando, en la primera parte del mil setecientos, se abordó la organización de la Marina, se buscó un control más directo sobre los cirujanos que iban a servir en los buques. Las medidas adoptadas fueron la creación del puesto de Cirujano Mayor de la Armada, al que en 1728 se le concedieron plenos poderes en todo lo concerniente a los cirujanos de Marina -en detrimento del Protomédico de la Armada y por tanto también del Tribunal del Protomedicato-, y la creación en el Hospital de Cádiz, al año siguiente, de un anfiteatro y una Escuela de Anatomía.

En un segundo paso, y dentro del empujón renovador que a mediados de siglo se dio en el seno de la Marina, se estableció allí en 1748 un Colegio de Cirugía. Su artífice, Pedro Virgili, cuidó de que a lo largo de los tres años de estudios se aunase la experiencia práctica a sólidos conocimientos anatómicos. Además, argumentando que el cirujano embarcado tenía que atender también a enfermedades que requerían socorro médico, y que las medicinas podían terminarse en viajes dilatados, Virgili consiguió que los estudiantes de cirugía obtuviesen algunos conocimientos de medicina, practicando al lado de los médicos del Hospital, y que se les adistre en la preparación de fármacos ${ }^{29}$.

28 Sobre la situación de la cirugra, véase M.E. BURKE, The Royal College of San Carlos. Surgery and Spanish Medical Reform in the Late Eighteenth Century, Durham: Duke Univ.Press, 1977, especialmente el Cap.II.

29 Véase D. Ferrer, Biografla de Pedro Virgili, Barcelona: Colegio Oficial de Médicos, 1963. Su Historia del Real Colegio de Cirugta de la Armada de Cádiz, Cádiz, 1961, no afiade otras noticias de interés para nuestros propósitos. El Memorial de Virgili, en págs. 87-94. 
Pero la nueva institución no sólo servía para proveer a la Armada de cirujanos entrenados; también constituyó la primera vía para la reivindicación profesional frente a la medicina. A partir de 1751, los alumnos más adelantados son enviados a París, Montpellier, Leiden y Bolonia para ampliar estudios, y a su regreso, en 1757, pasan el examen ante el Tribunal del Protomedicato obteniendo los títulos de medicina y cirugía. Ese mismo año de 1757 el Colegio obtuvo la prerrogativa de expedir el título de cirujano latino, y para entonces el programa de estudios, ampliado a cuatro años, comprendía también los estudios de humanidades correspondientes a un Bachillerato en Artes.

Gracias asimismo a la iniciativa de Virgili, el Ejército seguiŕa en 1760 los mismos pasos que la Marina creando otro Colegio de Cirugía en Barcelona. Tanto a éste como al de Cádiz se les dotó de un moderno plan de estudios que abarcaba fisiología y patología, osteología, anatomía, terapéutica y operaciones quirúrgicas. Además, la profesionalización del cirujano en Cataluña quedaba definitivamente configurada al margen de la asistencia a las lecciones universitarias y el examen ante el Protomedicato. A partir de la creación del Colegio de Barcelona, se ordenaba que todos las asociaciones profesionales y gremios de cirugía del Principado quedasen sometidos al mismo, y sólo el Colegio, no el Protomedicato, podía habilitar allí para el ejercicio de la profesión ${ }^{30}$.

Los cirujanos civiles, que seguían sometidos a la autoridad del Protomedicato, buscaron asimismo reivindicarse. Pero el triunfo fue difícil, y sólo en 1787, de la mano de Antonio Gimbernat, se podrá inaugurar en Madrid el Real Colegio de Cirugía de San Carlos ${ }^{31}$. Se trataba de una institución destinada a

30 Véase M.Usandiaga Soraluce, Historia del Real Colegio de Cirugia de Barcelona (17601843), Barcelona: Instituto Municipal de Historia, 1964.

31 Los distintos informes cursados previamente a su fundación constituyen, con el omnipresente y espinoso trasfondo de la autogestión, toda una polémica sobre la necesidad y alcance de los saberes convenientes a un cirujano. Para el Protomedicato y la Academia de Medicina madrileña (un colegio profesional fundado en 1732), la cirugía era una profesión artesanal que no precisaba un alto nivel de conocimientos para el desempeño de sus funciones cotidianas. Los cirujanos, por su parte, apoyados por Campomanes, fiscal del Consejo de Castilla, buscan equiparar cirugía y medicina, proponiendo enseh́anzas que invadían peligrosamente el terreno tradicional de ésta. De la dureza del enfrentamiento da idea la respuesta del Colegio de San Fernando (un colegio profesional de cirujanos establecido en Madrid en 1748) a Campomanes, cuando éste le consulta sobre la propuesta de la Facultad de Medicina de Salamanca de reformar sus cursos para cirujanos. El Colegio responde señalando la carencia de preparación que, como tales, tienen los médicos en el campo de la cirugia, y que ésta y ula injustificada superioridad que pretenden poseer sobre los cirujanos, son las razones de que la cirugía española haya 
impartir enseñanzas elitistas, que requería para el ingreso en sus aulas tres años de latín y lógica, un año de estudios en geometría, y otros tantos en álgebra y física experimental ${ }^{32}$.

La definitiva resolución del contecioso entre médicos y cirujanos a favor de éstos llegó con la fundación del Colegio de San Carlos, pero no sin pasar, en 1780, por la reforma del Protomedicato, que a partir de esa fecha se dividía en tres Audiencias independientes para Medicina, Cirugía y Farmacia. Cuando, fugazmente, se excluya en 1799 la medicina de las universidades, su docencia se confiaría a los Colegios de Cirugía. Si bien habría que esperar todavía casi un siglo, la fusión de medicina y cirugía se había anunciado ya con ello.

La farmacia, por su parte, presentaba a principios de siglo una situación distinta de la cirugia. Con una fuerte organización gremial que venía a constituír, en la práctica, una auténtica autonomía, no se dieron en su seno especiales urgencias renovadoras. Tradicionalmente, para convertirse en boticario sólo se exigía el conocimiento del latín y cuatro años de práctica con un maestro boticario que tuviese abierto un establecimiento. Los nuevos tiempos, sin embargo, obligaron a los gremios y colegios profesionales de boticarios a apostar, siquiera nominalmente, por los nuevos saberes, en un intento de mantener incólumes sus privilegios. Cuando, con la llegada al trono de Carlos III, los boticarios valencianos, madrileños y barceloneses soliciten la renovación de aquéllos, manifestarán su apuesta por una renovación de las enseñanzas, pero sólo los catalanes propondrán institucionalizarla mediante la creación de cátedras de

llegado a su actual decadencia». Citado en M. E. BURKE, The Royal College..., op. cit., pág. 56. Abundando en el tema, se puede citar el memorial elevado por los cirujanos de Familia, quienes piden el autogobierno sefialando estas mismas razones. El Tribunal, por su parte, arremete en su respuesta contra los cirujanos sin distinción de clases, afirmando que son "muchos de ellos sin talento, algunos que hasta el leer ignoran, y casi todos mal educados por criarse en barberias, sin aplicación a buenos libros ni instrucción alguna de sus maestros». Además, los más hábiles cirujanos use dedican más a las materias y tratados de Medicina, que a los útiles y necesarios de su arte, aspirando a ser reputados por médicos con la sola tintura que toman de un recetario». Citado por M. C. CAlleja Folguera, La reforma sanitaria..., op. cit., pág. 111.

32 M.E. BuRKE, The Royal College..., op.cit., pág.87. Esto tuvo su efecto sobre la matrícula de alumnos; sólo tres cumplieron estos requisitos al abrirse la nueva institución. Los estudios se dividían en teóricos y prácticos. Dentro de los primeros, se establecían cátedras de anatomía, fisiología e higiene, patología y terapéutica, y materia médica; los prácticos contaban con cátedras de enfermedades quirúrgicas, obstetricia y enfermedades venéreas, operaciones y uafectos mixtos" (enfermedades que presentaban a la vez sintomas internos y externos). Esta última cátedra se convertiría en 1795 en la de teoría y práctica médicas. Ibid., pág. 90. 
Farmacia, Química y Botánica, dotadas con un jardín botánico y un laboratorio químico ${ }^{33}$.

Este proyecto se acogió favorablemente, pero al desinterés de los gremios se unió la oposición del Tribunal del Protomedicato, para el que los nuevos proyectos significaban la pérdida de control sobre el ramo de la Farmacia. Con la reforma de este Tribunal en $\mathbf{1 7 8 0}$ se barajó la idea de establecer en Madrid un centro docente para la enseñanza de la farmacia, la botánica y la química, que sirviese de modelo para la fundación de otros centros, ordenándose al Colegio de boticarios madrileño la elaboración de un proyecto. Pero éste vio retrasada su aplicación a causa de las reformas emprendidas en el Real Jardín Botánico.

El Real Jardín Botánico se fundó en 1755, dependiente del ramo sanitario. El cargo de Director debía recaer en el Protomedicato, el Subdirector debía ser el Presidente de la Real Botica, y la institución contaría con dos catedráticos ${ }^{34}$. Estas circunstancias prefiguraban ya lo que sería la futura andadura de la institución, que se inició firmemente con el traslado a su actual emplazamiento en el Paseo del Prado y el nombramiento de Casimiro Gómez Ortega como primer catedrático. Como es sabido, la institución ejerció una política muy activa en relación con las expediciones ultramarinas ${ }^{35}$, y también iba a configurarse como centro docente de la farmacia. A principios de la década de los ochenta la docencia se estructuró en cuatro cursos, dos de botánica y dos de

33 Acerca de los planes de estudio propuestos en la época por los colegios de boticarios, véase G. FOLCH Jou, "Problemática de las enseñanzas de Farmacia en la Espania del siglo XVIII", Anales de la Real Academia de Farmacia, 48 (1982), págs. 285-302.

34 Además, tanto el Director como el Subdirector, por sus cargos, formaban parte de la Real Academia Médica Matritense. F.J. PUERTo SARMIENTO, La ilusión quebrada. Botánica, sanidad y politica cientifica en la España ilustrada, Barcelona/Madrid: Serbal/CSIC, 1988. En general, sobre la historia del Jardín véanse, además de la biografla de Casimiro Gómez ortega citada en la nota siguiente, M. COLMEIRO, "Bosquejo histórico y estadístico del Jardín Botánico de Madrid", Anales de Historia Natural, 1985, págs.211-345; C. AÑON, Real Jardin Botd́nico de Madrid. Sus ortgenes: 1755-1781, Madrid, 1987; M. Carmen VIDAL CASERO, Aportaciones al conocimiento de la historia del Jardin Botánico de Madrid en sus inicios, Valencia, Universitat de València, 1994; J. L. Peset, «El jardín Botánico de madrids y sus relaciones con Francia», Asclepio 48(1) (1996), págs. 59-70; D. Soto ARANGo, Francisco Zea, un criollo ilustrado, Madrid, Doce Calles, 2000; y A. GonzAlez Bueno y R. RodrfGuez Nozal, Plantas americanas para la Esparia ilustrada, Madrid, Editorial Complutense, 2000.

35 Sobre ello véase J. PUERTo Sarmiento, La ilusión quebrada..., op. cit. Asimismo Ciencia de cámara. Casimiro Gómez Ortega (1741-1818), el cientifico cortesano, Madrid: CSIC, 1992. 
plantas oficinales, y se reiteró la obligación de asistir a los mismos por parte de los oficiales y aprendices de botica que ya se había señalado en $1762{ }^{36}$. Además, se creó el título de botánico, con el cual se distingufan los corresponsales del Jardín y sus alumnos. Este título, unido al de médico, cirujano o farmacéutico, daba preeminencia a su poseedor a la hora de optar a puestos o comisiones del Estado. En 1787 las enseñanzas se redondearon con el establecimiento de un laboratorio de química.

Las pretensiones docentes de la institución se trataron de extender desmedidamente a todo el ramo sanitario. Así, el Reglamento del jardín botánico establecido por la Armada en Cartagena en 1787, y vinculado asimismo al Jardín de Madrid, dictaba la obligación de médicos, cirujanos y boticarios a acudir a las enseñanzas de botánica ${ }^{37}$. No se lograron estas ambiciones, pues médicos y cirujanos contaban con instituciones específicas para su docencia; $y$, por su parte, los farmacéuticos buscarían su propio sendero, aunque carecerían de docencia propia hasta la centuria siguiente ${ }^{38}$.

\section{Las academias militares}

Tradicionalmente, el aprendizaje de la profesión militar se había desarrollado en la vida de guarnición y en el campo de batalla. Pero la tecnología, siempre presente de una u otra forma en los quehaceres bélicos, había cobrado un creciente protagonismo en tres frentes: ingenieros militares, artilleros y marinos debían poseer en la época conocimientos especializados para el desempeño de sus funciones. En España, una de las primeras necesidades de la nueva dinastía borbónica fue la reorganización de las fuerzas armadas, y para ello se optó por crear instituciones docentes que formasen a la nueva oficialidad. Las primeras en abrir sus puertas fueron la Academia de Guardias Marinas de Cádiz, en 1717, y la Real Escuela Militar de Matemáticas de Barcelona, en 1720. Ambas venían a constituírse en centros vertebradores de

36 Sobre el tema concreto de la trayectoria docente de la institución, véase M. A. PUIG SAMPER, "La enseñanza de la botánica en la España ilustrada: El Jardín Botánico de Madrid», en La Real Expedición Botdnica a Nueva España, 1787-1803, Madrid: CSIC, 1987, págs. 59-78.

37 A. Lafuente, J. Puerto y M.C. CallejA, "Los profesionales de la sanidad...", op.cit., pág. 90. Véase allí un somero análisis de la situación y de su desenlace.

38 Para este complejo proceso, véase M.C. CALLEJA, La reforma sanitaria..., op.cit. 
nuevos cuerpos castrenses: marinos e ingenieros. La Escuela de Barcelona contaba con un importante precedente en la Academia Real y Militar que había dirigido en Bruselas Sebastián Fernández de Medrano, cuya tradición, en cierto modo, continuó. Estaba destinada a oficiales y cadetes, y en ella se preveía el adiestramiento tanto de los mandos del ejército en general como de los ingenieros en particular. Sus enseñanzas comprendían la aritmética, geometría, fortificación, mecánica, nivelación y dibujo ${ }^{39}$. La Academia gaditana, por su parte, diseñada como un pensionado con disciplina militar, ofrecía a los jóvenes procedentes de una nobleza baja una vía de ascenso social y una formación acorde con su clase. Las enseñanzas, conformes a esto, aunaron, junto a la tradicional formación de los marinos en matemáticas, pilotaje y maniobra, asociadas a las disciplinas castrenses de fortificación y dibujo, las lenguas, la danza y la esgrima ${ }^{40}$.

En ambas instituciones se planteó prestamente la polémica sobre las utilidades que los saberes teóricos podían rendir a la formación militar, si bien en Cádiz, donde se trataba de crear un nuevo colectivo, el conflicto se presentó bajo la forma de la resistencia de los cadetes a someterse a la disciplina del estudio y de la incomprensión de algunos mandos de la Compañía hacia el proyecto. En Barcelona, donde los colectivos implicados tenían más fuerte arraigo, el debate fue más vivo ${ }^{41}$. Pero, en cualquier caso, lo que estaba fuera de duda era que las enseñanzas debían estar orientadas a las aplicaciones prácticas, y que no se podían impartir en el seno de instituciones de índole religiosa o civil ${ }^{42}$.

39 Sobre el Cuerpo de Ingenieros y la Academia de Barcelona, véase la obra de H. CAPEL, J.E. SANCHEZ y O. MONCADA, De Palas a Minerva. La formación cientifica y la estructura institucional de los ingenieros militares en el siglo XVIII, Barcelona/Madrid: Serbal/CSIC, 1988. Las materias citadas, en la pág. 124.

40 Acerca de la Academia de Guardias Marinas, véase A. Lafuente y M.A. Sellés, El Observatorio de Cádiz (1753-1831), Madrid: Ministerio de Defensa e Instituto de Historia y Cultura Naval, 1988. El plan de estudios inicial, en la pág. 52.

41 Véase A.Lafuente, "La enseñanza de las ciencias durante la primera mirad del siglo XVIII", en Estudios dedicados a Juan Peset Aleixandre, 3 vols, Valencia: Univ.de Valencia, 1982, vol .2, págs. 477-492. También A. LAFUENTE y M. A. SELlês, "La milicia academizada: el conflicto entre la pluma y la espada durante la primera mitad del siglo XVIII", en Educación e Ilustración en España. III Coloquio de Historia de la Educación. Barcelona: Univ. de Barcelona, 1983, págs. 245-253.

42 Asi, en su Proyecto, o Idea sumaria, para la formación, Gobierno y permanente establecimiento de Academias Reales y Militares de Mathematicas y Fortificaciones..., Verboom indica que "aunque no faltan en sus Reales Dominios Colegios y escuelas particulares a donde se dan Rudimentos de Matemáticas, y Fortificaciones; tengo por sin duda según lo 
El Plan de 1711 había creado el nuevo Cuerpo de Ingenieros en el seno del Ejército y sus miembros, hasta la fecha supeditados al Capitán General de Artillería, buscaron y consiguieron una creciente autonomía. El proyecto de su organizador, Próspero de Verboom, era formar una Academia militar que, dominada por los ingenieros, les procurase no sólo el control sobre su propia formación, sino también sobre la de artilleros y oficiales del ejército en general. Sus pretensiones se veían apoyadas por el carácter de las prestaciones que se demandaba al nuevo cuerpo: constituídos en el primer colectivo técnico organizado del pais, las Ordenanzas dictadas en 1718 inclulan muy principalmente entre sus funciones las de asumir el reconocimiento de las potencialidades económicas del territorio nacional y las de intervenir en las obras públicas necesarias para su desarrollo ${ }^{43}$.

Pero si Verboom buscaba una institución destinada a la formación especializada de ingenieros y controlada por éstos, su primer director, Mateo Calabro, procedente de la artillería, se resistía a esta subordinación jerárquica y defendía unos estudios de carácter más general ${ }^{44}$. De hecho, parece que en la década de los treinta se planeó la fundación de diversas academias militares controladas por los ingenieros; incluso se llegó a elaborar un nuevo plan de estudios para la Academia de Guardias Marinas. Esto no se llevó a la práctica, pero la disparidad de opiniones entre Verboom y Calabro se resolvió a favor del primero, cesando Calabro en su puesto en 1738.

Tanto en la Academia de Guardiamarinas de Cádiz como en la Escuela Militar de Barcelona, los debates iniciales acabaron por dar paso a una situación

demuestra la continua experiencia, que si es alguno el fruto que ellas producen, es tan parvo como desabrido, porque la mente del aplicado se ampara en los preceptos especulativos, suele dirigirlos tan confusa e insustancialmente, que faltándole la oportunidad y la práctica del modo de su aplicación; viene, cuando no sea a repugnarlos del todo por abstractos, a servirse de ellos a lo más, para solo objeto de entretener la ociosidad». Cit. en A.Lafuente, "La enseñanza de las ciencias...", op. cit., pág. 480. También, en un Discurso para el establecimiento de Academias Reales de Matemáticas Militares (sin fecha ni firma; atribuído a Verboom), se afirmaba este carácter militar que deblan tener las enseñanzas, indicando "que las partes que pertenecen al arte Marcial, no se pueden aprender, en conclusiones con el artificio y sutileza de la lógica". Este carácter no se da uen los religiosos y otros Maestros de Matemáticas especulativas, cuya enseñanza se reduce a puras curiosidades, y primor de las expresiones (...). Además que los religiosos, y eclesiásticos penden más de la obediencia de sus superiores que de la del Rey." Ibid., pág. 478. Aunque no sucediera así en la Academia de Barcelona, las de Cádiz y Segovia tuvieron que recurrir a un profesorado civil; en el caso de esta última, se nombró a un jesuíta, el P. Eximeno, como Director de Estudios.

43 Sobre estas Ordenanzas, véase H. CAPEL et al, De Palas..., op.cit., págs. 34-37.

44 ibid, pág.117. 
de relativa estabilidad. Los ingenieros habían logrado sus reivindicaciones en el seno del Ejército, y el nuevo Cuerpo, de la mano de Verboom, se había convertido en una corporación profesional jerarquizada, en donde la escala de mando concordaba con la capacitación profesional, la cual aunaba la experiencia con la formación científica ${ }^{45}$.

A mediados de siglo se inició una etapa de cambios, de la mano de la politica de renovación de las fuerzas armadas emprendida por el marqués de la Ensenada. En la Academia de Guardias Marinas, gracias a Jorge Juan, nombrado Comandante de la Companía de cadetes, se produjo una completa renovación del profesorado y de los estudios, buscando mayores cotas de capacitación mediante unos saberes más actualizados. También se creó el Cuerpo de Pilotos de la Armada, con el fin de resolver la endémica escasez de estos profesionales, cuyas atribuciones, por otra parte, habian venido a invadir los nuevos oficiales surgidos de la academia gaditana.

De hecho, desde principios del siglo XVI los pilotos, responsables del gobierno técnico del buque, hab́an cursado estudios teóricos a cargo de los cosmógrafos de la Casa de Contratación de Sevilla. Tales enseñanzas no se impartían al abrirse el setecientos, y los estudios en el Colegio de San Telmo de la misma ciudad dejaban mucho que desear ${ }^{46}$. De modo que los buenos pilotos eran cada vez más escasos. Así, el procedimiento de la marina de guerra de contratar a pilotos para embarques específicos se hizo inviable $y$, tras un breve interludio en el que se contrató a un grupo de ellos mediante un programa de media paga cuando no estaban embarcados, se abordó la creación de un cuerpo específico ${ }^{47}$. Esto

45 En la década de los treinta se ensefiaba aritmética, geometria, levantamiento de planos, fortificación y asedio de plazas, artillería, geografía y dibujo. Estas enseñanzas, que no se apartaban de lo usual en estos profesionales, son más modestas que las recogidas en el plan elaborado en 1724 por Mateo Calabro, quien extendía las materias a la cosmografia, arquitectura civil y mecánica (estática, maquinaria e hidrostática). Ibid., pág. 116. La evolución de las enseñanzas no presentó, a partir de ese momento, grandes puntos de inflexión. Véase H. CAPEL, "Cursos manuscritos y textos impresos en la enseñanza científica de los ingenieros militares", Asclepio, 39 (2) (1987), págs. 161-199.

46 Esta institución se fundó en 1681, con la misión de acoger nifos huérfanos e instruírlos en el pilotaje, para remediar la endémica escasez de estos profesionales. Véase M.A. SELLÉS y A. LAFUENTE, "La formación de los pilotos en la Espáńa del siglo XVIII", en J.L. PESET et al, La ciencia moderna y el Nuevo Mundo, Madrid: CSIC y SLHCT, 1985, págs.149-191.

47 También en el caso del pilotaje se debatió la utilidad de los saberes teóricos frente a una práctica tradicional. Así, Pedro Manuel Cedillo, profesor del Colegio de San Telmo y autor de 
también venía a resolver una espinosa situación originada por el enfrentamiento a bordo de los buques entre los pilotos y los nuevos oficiales formados en la Academia. Aquéllos se quejaban de intrusismo en sus funciones, de desprecio a su categoría profesional, y de las malas consecuencias de unas decisiones que, tomadas desoyendo su parecer, ocasionaban graves accidentes. Pero si los pilotos acusaban a estos oficiales de aplicar unos conocimientos teóricos mal entendidos por falta de formación práctica, desde el ministerio se desoían sus reivindicaciones a causa de su escasa profesionalidad ${ }^{48}$.

El problema se zanjó con la creación del Cuerpo de Pilotos de la Armada y el establecimiento de una Escuela de Pilotos en cada Departamento marítimo. En ellas se impartirían unos estudios discretos y prácticos, adecuados al carácter de cuerpo profesional intermedio que para este colectivo preveĺan las Ordenanzas de Marina de $1748^{49}$. La supeditación a los oficiales de la Academia de Cádiz quedaba así también establecida por la subordinación en conocimientos. En las páginas introductorias al Compendio de Navegación para uso de los Caballeros Guardias Marinas (Cádiz, 1757) que redactó Jorge Juan

una Trigonometria aplicada a la navegación (Sevilla, 1717), se ve precisado a defender su obra subrayando «el poco fundamento, que tiene el vulgo Náutico, en decir proverbialmente, que desde que hay Senistas (que asi llaman a los Profesores de la Trigonometría) se pierden los Navios. Es verdad que si el tal proverbio habla de los que se entrometen a Senistas, sin tener fundamento alguno, de la Trigonometría, ni saber los principios que suponen para las resoluciones son ciertos, dudosos, o falsos, no carece de razón. Pero esta proporción no comprende al que es verdadero Profesor de esta facultad, y es práctico en la navegación...". Citado en M.A. SELLÉS y A. LAFUENTE, "La formación de los pilotos...", op.cit., pág. 155.

48 Así por ejemplo Juan González de Uruefia, en su Delineación de lo tocante al conocimiento del punto de longitud...(Madrid, 1740) defendía que las matemáticas no eran precisas para el pilotaje y que los dictámenes acertados eran fruto de la experiencia, y añadía que: «Lo contrario se ha experimentado comúnmente, con los que sólo se han fiado de haber estudiado por especulativa, reglas, $y$ principios Matemáticos, o Geográficos, $y$ por esto se han tenido por más inteligentes. De esto se han visto más ejemplares en este Siglo, que en otro, en el cual por querer dar sus dictámenes algunos Oficiales Militares, con sólo el fundamento de principios Matemáticos, se han experimentado las pérdidas tan frecuentes que son notorias..... Citado en ibid., pág. 156. Por su parte, en 1738 el marqués de la Ensenada subrayaba «la corta suficiencia de los más de ellos y que sólo son Pilotos en nombre por tenerse por experimentado en las repetidas Campafias hechas al Mediterráneo la precisión de llevar dos en cada navio por su total ignorancia". Citado en ibid., pág. 163.

49 En dichas Ordenanzas se establecía la enseñanza de «la Navegación, y el uso de los Instrumentos prácticamente del modo más breve, y comprensible, que fuere posible; $y$ a los que estuvieren impuestos en la Práctica, se dará alguna luz de los principios Teóricos, dictándoles los precepros más precisos de Geometría, y Astronomía..... Citado en ibid., pág. 164. 
para la enseñanza en la Academia, se afirmaba claramente que se inclứa "la razón y demostración de cuanto se practica, aún de las menudencias más triviales, a fin de que en cualquier ocasión, no servilmente, sino como necesita hacerlo un Oficial, puedan V.ms. exponer sus dictámenes con el mayor acierto" ${ }^{50}$.

Por su parte, los ingenieros no introdujeron, en esta etapa, significativos cambios en sus planes de estudio. Pero la Escuela de Barcelona agrupaba a ingenieros y artilleros, con neto predominio de los primeros. Prácticamente desde su establecimiento, los artilleros buscaron su consolidación como cuerpo independiente ${ }^{51}$. El éxito fue parcial, lográndose el establecimiento de Escuelas de Artillería en Barcelona y Cádiz en 1751. Los objetivos sólo se lograrán plenamente cuando, en 1762, se produzca la separación definitiva de ambos cuerpos y abra sus puertas en Segovia, dos años más tarde, la Academia del Cuerpo de Artillería, con un modelo de pensionado para jóvenes nobles similar al establecido en Cádiz para la Marina. La Oración inaugural leída por su primer profesor, el padre Eximeno, subtitulada «Oración sobre la necesidad de la teoría para desempeñar en la práctica el servicio de Su Majestad", deja bien clara la decidida vocación científica de la Academia y del cuerpo de artillería en general ${ }^{52}$.

so Que la superioridad en el mando debía ir acompanada de una superioridad en conocimientos es algo que sancionará Floridablanca en su Instrucción reservada a la Junta de Estado. El artículo 186 decía que: "No es necesario encargar que se ponga todo el cuidado posible en el aumento y perfección de las escuelas de náutica y pilotaje, a la que deben asistir los guardias marinas y oficiales, pues si éstos han de mandar a los pilotos y subalternos, justo será que sepan tanto y más que ellos. En este particular es muy conveniente tomar providencias activas, y que sepan los oficiales de Marina que sin la ciencia necesaria de los principios y arte de navegar, no han de ser promovidos." En Andrés Muriel, Historia de Carlos $I V$, BAE, 2 vols., Madrid, 1959. Vol. 115, pág. 351.

51 Siendo una de sus principales reivindicaciones la amplitud y especificidad de los saberes necesarios para el buen desempeno de su oficio. Según los artilleros, su disciplina es uun arte sumamente ingenioso, diff́cil y vastísimo, que para consumarse en él ninguna diligencia está de más, ninguna aplicación sobra, ni muchísimo tiempo bastan. Escrito de 26 de diciembre de 1750 en refutación de otro de Juan Cermeño contrario al establecimiento de las Academias de Artillería, citado en H. CAPEL, J.E. SÁNCHEZ y O. MONCADA, De Palas a Minerva, op.cit., pág. 158. Sobre los precedentes de la ensefianza de la artillería y las polémicas con los ingenieros a mediados del siglo, véanse las páginas 147ss.

52 En la dedicatoria de los caldetes al rey se afirma que el fin es "lograr por medio de la buena educación el conocimiento científico, necesario e inexcuasable para desempeñar el servicio de V.M. en la ardua y distinguida carrera de las Armasm. A. Eximeno, Oracion que en la abertura de la Real Academia de Caballeros cadetes del Real Cuerpo de Artilleria nuevamente establecida por S.M. en el Real Alcdzar de Segovia dijo el P..., Profesor Primero de dicha Academia. En el dia 
El desarrollo de las instituciones docentes militares habla concentrado en ellas todo el esfuerzo de renovación en el campo de los saberes físico-matemáticos, hasta tal punto que se ha hablado de una militarización de las actividades científicas ilustradas ${ }^{53}$. Así, cuando los proyectos de fundación de una Academia general de ciencias generados a mediados de siglo quedaron en suspenso, las demandas gubernamentales en materias científicas y tecnológicas siguieron recayendo sobre el estamento militar, y este proceder llegó a tornarse habitual ${ }^{54}$.

Esta situación acabó por plantear el problema de la difícil búsqueda de equilibrio entre las utilidades de una formación científica y las necesidades concretas del desempeño de una formación castrense. El caso más agudo en este sentido fue el de la Marina. Los saberes relacionados con este ramo sufrirían durante el siglo un importante desarrollo, tanto por la aplicación de la mecánica al estudio de la construcción y maniobra navales, como por los nuevos métodos de determinación de la longitud en el mar y el desarrollo de la astronomía aplicada a la navegación. Con las reformas de mediados de siglo, Jorge Juan renovó los estudios en la Academia, introduciendo el estudio del cálculo infinitesimal e integral,

16 de Mayo de 1764, Madrid, 1764, s.p. Sobre la historia de esta institución, véase M. D. HeRrero FERNANDEZ-QUeSADA, La enseñanza militar ilustrada. El Real Colegio de Artilleria de Segovia, Segovia: Academia de Artilleria, 1990. Sobre los primeros años, E. Hidalgo CAMARA, "La etapa fundacional de la Academia de Artillería de Segovia: 1764-1779", en J. FerNANDEZ Pérez e I. GonzAlez TASCÓN (eds.), Ciencia, técnica y Estado en la España Ilustrada, Madrid: Ministerio de Educación y Ciencia y SEHCT, 1990, págs. 13-29. Para un estudio más detenido, véase su Ciencia e institución militar en la España ilustrada. El caso de la Artillería, Tesis Doctoral, Madrid: UNED, 1993.

53 Véase A. LAFUENTE y J.L. PESET, "Militarización de las actividades científicas en la España ilustrada (1726-1754)", en J.L.Peset et al (eds), La ciencia moderna y el Nuevo Mundo, op.cit., págs. 127-147. El volumen del gasto implicado llevó a su racionalización, véase asimismo "Las Academias Militares y la inversión en ciencia en la España ilustrada (1750-1760)", Dynamis, 2 (1982), págs. 193-109.

54 Las comisiones al extranjero con misiones que iban más allá de la mera ampliación de estudios fueron muchas y variadas. Véase, como muestra, A. LAFUENTE y J.L. PESET, «Política cientifica y espinaje industrial en los viajes de Jorge Juan y Antonio de Ulloa (1748-1751)", Melanges de la Casa de Veldzquez, 17(1981), págs. 233-262, y J.Helguera QUIJADA, «Las misiones de espionaje industrial en la época del Marqués de la Ensenada, y su contribución al conocimiento de las nuevas técnicas metalúrgicas y artilleras, a mediados del siglo XVIII", en $\mathrm{M}$. ESTEBAN PIÑEIRo et al (eds.), Estudios sobre historia de la ciencia y de la técnica. IV Congreso de la SEHCT, Valladalid: Junta de Castilla y León, 1988, vol. 2, págs. 671-695. Sobre la siempre postergada Academia de Ciencias, véase A. Rumeu de Armas, origen y fundación del Museo del Prado, Madrid, 1980. 
y acometió la elaboración de un nuevo sistema de construcción naval. Muchos cadetes y oficiales se mostraron contrarios a este endurecimiento de los estudios, y pasados algunos años, tras la caída del marqués de la Ensenada y la consiguiente pérdida de favor de Juan, se relajaron las enseñanzas.

Entretanto, se habían puesto a prueba con éxito los nuevos métodos de determinación de la longitud en el mar, y urgía tanto introducirlos en el plan de estudios como asimilar en el país las tecnologías que posibilitaban su aplicación ${ }^{55}$. Ya en 1776, al crearse nuevas Academias de Guardias Marinas en El Ferrol y Cartagena, José de Mazarredo, al frente de esta última, había reivindicado la necesidad de recuperar el nivel en los estudios ${ }^{56}$. Sus recomendaciones fueron pasadas por alto hasta que finalmente, en 1783, el problema cristalizó cuando se emprendió un ambicioso programa hidrográfico en las costas peninsulares y americanas. Los consiguientes debates sobre los estudios llevarían a un equilibrio, recuperándose la disciplina académica e introduciéndose las novedades sobre la determinación de la longitud. Este equilibrio ya no llegaría a alterarse. Así cuando, en 1787, apareciese el Tratado de navegación de José de Mendoza y Ríos, en donde se reclamaba la introducción de la astronomía náutica, la obra se juzgaría excesiva e inadecuada para la enseñanza en las Academias ${ }^{57}$.

La reforma del plan de estudios para las Academias de Guardias Marinas dejó claro que éstos no podían alcanzar el nivel suficiente como para desempeñar con garantías de éxito las comisiones hidrográficas que se proyectaban. La inexistencia de otras instituciones científicas que pudiesen cumplir tal cometido, unida a la habitual costumbre de la autogestión, hizo inevitable la definición de un escalón superior de conocimientos. Este se impartió a través del denominado Curso de Estudios Mayores, el cual abrazaba en toda su

55 Véase un resumen del tema en A. LAFUENTE y M.A. SELLES, "The problem of longitude at sea in the 18th century in Spain", Vistas in Astronomy,28(1985),págs.243-250. Para un estudio más detenido, M.A. SEllés, Navegación astronómica en la España del siglo XVIII, Madrid: UNED, 2000.

56 Los guardias marinas que llegan a oficiales, escribla al ministro de Marina en 1777, «han olvidado facilisimamente los rudimentos que aprendieron y el que por necesidad hacen vanagloria únicamente de dedicarse a la Maniobra como la parte brillante de un Oficial, muy satisfechos de sí mismos si progresan en ella y con la fatalísima rastra de imbuír a los que siguen que no es necesario más para ser un buen Oficial de Marina". Citado en A. LAfuente y M. SELLES, El Observatorio de Cadiz, op.cit., pág. 214.

57 Sobre esta obra, véase M.A. SELLES «La astronomía náutica en la Espania ilustrada. El Tratado de Mendoza y Ríos», Asclepio, 39(2) (1987), págs. 33-47. 
profundidad aquellas disciplinas relacionadas con la navegación y la hidrografía. La docencia, que se llevó a cabo en las tres Academias, estuvo destinada a oficiales voluntarios ${ }^{58}$. Ello no obstante, sirvió para plantear claramente la incompatibilidad existente entre un cientifico y un oficial de marina. Cuando, por estas fechas, se reactive el Observatorio erigido a mediados de siglo por Jorge Juan como anexo a la Academia de Cádiz, los oficiales allí destinados expresarán su parecer de que éste deberf́a acometer las más altas tareas astronómicas, pero asistido por profesionales que, aunque procedentes de la Armada, deberían hallarse exonerados de todas sus responsabilidades militares. La intervención de José de Mazarredo trataría de enderezar la situación: Con el Curso de Estudios Mayores no se buscaban astrónomos profesionales, sino oficiales de Marina perfectamente impuestos en la profesión ${ }^{59}$. Pero con ello se había llegado al límite del proceso que, iniciado a principios de siglo, buscaba la formación de unas fuerzas armadas profesionalizadas por la vía de los conocimientos cientificos. Para muchos la ciencia y la milicia, a partir de este momento, debían seguir caminos divergentes ${ }^{60}$.

\section{Ingenieros civiles y otras profesiones técnicas}

La presencia del estamento castrense, como colectivo más preparado, en múltiples desempeńos de orden cientifica y tecnológica ajenos a su instituto, comen-

58 Sobre dichos estudios, M.A. Selles y A. LAfuente, "Sabios para la Armada: El Curso de Estudios Mayores de Marina en la Espafia del siglo XVIII", en J.L. PESET (ed), Ciencia, vida y espacio en Iberoamérica, 3 vols., Madrid: CSIC, 1989, vol.3, págs.485-504. Más extensamente, en A. LAFUENTE y M.A. SELLES, El Observatorio..., op.cit., págs. 203 ss.

59 "(...)el interés inmediato de la institución de los Estudios - decía- no es formar sabios de Bufete, objeto más propio de cualquiera Academia mediterránea, sino de enriquecer a los que los hicieron de un modo que sucesiva y respectivamente puedan coronar con el timbre de sabios las fatigas de la profesión y el desemperio de sus comisiones que los vayan conduciendo a los grados superiores, a fin de asegurar mejor así el éxito de sus cargos Militares y civiles en los mandos de los Departamentos, Escuadras, y otras expediciones (...)m. Mazarredo a Malaspina, "Instrucción provisional del método de servicio y tareas de los Oficiales destinados al Real Observatorio de Cádiz», Madrid, 19 de diciembre de 1788. Citado en A. LAFUENTE y M. A. SELLÉs, El Observatorio..., op. cit., pág. 256.

6o El mismo VARGAS PONCE, en su Elogio histórico a D.Antonio de Escaño (1816), no dudaría en denunciar el excesivo énfasis puesto en la formación teórica de los cadetes. Afirmaba que «...se pide al oficial que de todo entienda hasta poder mandarlo todo; que sepa dar vida a la muerta e intrincada máquina de un navio por medio de mecánica muy sabia; que gobierne una 
zará a dejar paso, en la última parte del siglo, a la actuación de cuerpos profesionales formados por miembros civiles. Tal fue el caso de los ingenieros cosmógrafos (salvando, desde luego, su estructura de corte militar), de los de caminos, y de los de minas. Se trata de actuaciones promisorias, pero tardías, que comportaron la fundación de centros docentes comprometidos con la modernidad.

Los ingenieros cosmógrafos nacieron en el seno del Observatorio de Madrid. Durante casi todo el siglo, la única institución de carácter astronómico había sido el observatorio de Marina, anexo a la Academia de Guardias Marinas de Cádiz. Tan sólo en 1790 se pondría la primera piedra del Observatorio madrileño, institución destinada a formar parte del complejo que eventualmente cristalizaría en una Academia nacional de Ciencias ${ }^{61}$. En esta fecha, a la par que se inició la construcción del edificio, se estableció una Escuela de Astronomía en la que su Director, Salvador Jiménez Coronado, comenzó a impartir clases regulares. El profesorado creció al incorporarse a la docencia los alumnos más adelantados, estableciéndose cursos de astronomía física, astronomía geométrica y meteorología. También se puso bajo la dependencia de la Escuela un taller de construcción de instrumentos, que impartía enseñanzas de matemáticas, astronomía y óptica aplicadas a este fin.

Este plan iba a verse desvirtuado por la creación del Cuerpo de Ingenieros Cosmógrafos de Estado en 1796, al que se le encomendaba el cartografiado del interior de la Península. Se trataba de una tarea ya urgente, postergada desde mediados del siglo, y que venía a complementar el levantamiento hidrográfico que había realizado la Marina ${ }^{62}$. El personal del Observatorio, sin por ello

ciudad flotante de tan variadas atenciones; que saque del cielo diarias noticias, que no puede leer en otro volumen; que luche con los elementos y los enfrente y domestique; que gobierne con pulso a dos especies de hombres tan desemejantes como marinos y soldados y que, con todo ese conjunto de dificultades preliminares, conozca a fondo los empefios de la guerra de tierra y marw. El Elogio está publicado por F. GuILLÉN, Madrid: Editorial Naval, 1962; la cita, en pág. 13. Sin duda estos términos responden en cierta medida a los recientes reveses navales. No dejan de ser significativos, sin embargo, de la ambición de los proyectos. La realidad de las ensehanzas, no obstante, fue más discreta. Sobre esto véase M.A. SELLÊs, "Ciencia y profesión militar en la Marina española del siglo XVIIIn, en E. BALAGUeR y E. GIMÉNEZ (eds.), Ejército, ciencia y sociedad en la España del Antiguo Régimen, Alicante: Instituto de Cultura "Juan Gil Albert", Diputación de Alicante, 1995, págs. 395-405.

61 Sobre la primera historia de la institución, véase J. TiNOCO, Apuntes para la historia del Observatorio de Madrid, Madrid: Talleres del Instituto Geográfico y Catastral, 1951.

62 Sobre estas cuestiones, H. CAPEL, Geografia y matemdticas en la España del siglo XVIII, Barcelona: Oikos-Tau, 1982, especialmente págs.132 ss. 
renunciar a sus puestos docentes, pasó a ocupar las plazas del nuevo cuerpo, por cierto curiosamente estructurado según una escala de mando de carácter militar. Pero los fondos para emprender la labor cartográfica no se hallaron, y pocos años después, en 1804, se extinguía este colectivo.

La iniciativa de creación de un cuerpo de ingenieros de caminos, surgida de Agustín de Betancourt ya en 1785, venía a incidir sobre otro problema cuya solución se había comenzado a abordar a mediados de siglo, el de las comunicaciones ${ }^{63}$. En este campo habla trabajado personal de diversa procedencia: extranjeros contratados, ingenieros militares, arquitectos o maestros de obras especializados. El nuevo cuerpo venía, así, a cumplir unas funciones que hasta la fecha habian formado parte del cometido de los ingenieros militares. El proyecto consistía en el establecimiento de una Escuela y de un Gabinete de Máquinas donde se conservasen modelos y planos de todas aquéllas consideradas de utilidad para las obras públicas y la industria. El Gabinete, abierto en 1792, precedió a la Escuela, que tardaría diez años en establecerse. Esta se configuraba como centro de enseńanza superior. Los alumnos aspirantes debían pasar un examen de ingreso de aritmética, álgebra, geometría, trigonometría plana y esférica, secciones cónicas, cálculo diferencial e integral y principios de física experimental ${ }^{64}$. De acuerdo con esto, el plan de estudios, desarrollado durante dos años, preveĺa materias especializadas. En el primero, mecánica, hidráulica, geometría descriptiva, empujes de tierras y bóvedas, estereotimia y dibujo; en el segundo, conocimiento de materiales, construcción de máquinas, puentes, encauzamiento de ríos y construcción de caminos y canales ${ }^{65}$.

La minería, por su parte, constituyó uno de los principales puntos de mira de los gobiernos ilustrados. En el País Vasco, como se vio, la Real Sociedad Bascongada de Amigos del País previó en su Escuela el establecimiento de cátedras de química, mineralogía y metalurgia. Las dificultades presupuestarias motivaron que éstas no pudiesen iniciar su andadura hasta que, en 1777 , se interesase por ellas la Marina. Gracias a su financiación la docencia de la química podría iniciarse en 1779, y en 1782 la de la mineralogía; su éxito fue relativo pues, pese

63 Sobre el origen y desarrollo de la Escuela, así como las vicisitudes de Betancourt y su otro personal, A.Rumeu de Armas, Ciencia y tecnología en la España ilustrada. La Escuela de Caminos y Canales, Madrid: Turner, 1980. Los precedentes, en págs. 246 ss.

64 Ibid., pág. 280.

65 Ibid., pág. 298. 
a la calidad del profesorado (Luis Proust, François Chabaneau y Fausto de Elhúyar) la asistencia a las clases, quizá por la novedad de la nueva especialización que se buscaba, fue escasa ${ }^{66}$.

En Almadén las enseñanzas impartidas por el Ingeniero Director a un grupo de alumnos durante el último cuarto del siglo no llegaron a constituírse en una Escuela formal ${ }^{67}$. Finalmente, se establecería en México el Seminario Metálico, que abriría sus puertas en 1792. Su plan de estudios se extendía a lo largo de cuatro años, estudiándose matemáticas en el primero, geometría práctica en el segundo, química en tercero y, finalmente, física subterránea en el último. En una segunda etapa, se introdujeron enseñanzas de corte humanístico, reforzándose la enseñanza de la física y las matemáticas con la introducción del cálculo infinitesimal, mecánica, electricidad, óptica y astronomía ${ }^{68}$.

Al margen de estos escalones superiores en la ensefíanza técnica, el número de centros docentes para la formación de profesionales de carácter intermedio, a uno u otro nivel, conoció una gran expansión en la última parte del siglo. En el caso del pilotaje, y a causa del Reglamento de Libre Comercio con América, se establecieron en los distintos puertos peninsulares numerosas escuelas de náutica, cuya reglamentación y planes de estudio serían controlados por la Armada ${ }^{69}$.

Otras profesiones, cuyos aprendizajes habían dependido hasta la época del mero adiestramiento empírico, tendrán la oportunidad de introducir en su desempeño una racionalidad de corte científico acorde con los nuevos tiempos. En este campo destaca la breve, pero en bastantes casos fructifera, labor de las Sociedades Económicas de Amigos del País, de las que con el estímulo

66 Véanse los clásicos estudios de L.Silván, Los estudios cientfficos en Vergara... y El qutmico Luis José Proust... op. cit. Sobre la fundación de la cátedra de química, en concreto, R. GAGO, «Bicentenario de la fundación de la Cátedra de Química de Vergara. El proceso de constitución", Llull, 2 (1978), págs.5-18.

67 A. Matilla TAsCÓN, Historia de las minas de Almadén, 2 vols., Madrid: Minas de Almadén e Instituto de Estudios Fiscales, 1987, vol. 2, págs. 148 ss.

68 Las obras clásicas sobre la institución son S. RAM1REZ, Datos para la historia del Colegio de Mineria. Recogidos y compilados bajo la forma de efemérides por su antiguo alumno el Ingeniero de Minas..., México, 1890, y J.J. IzQUIERDo, La primera casa de las ciencias en México. El Real Seminario de Mineria (1792-1811), México, 1958. Un breve panorama en J.L. PESET, «El Colegio de Minería de México", en M.A. Selles, J.L. PESET y A. LAfuente, Carlos III..., op.cit., págs. 233-245.

69 Sobre éstos, M.A. Sellés y A. LAFUENTE, "La formación de los pilotos...», op.cit. 
del Estado se crearon alrededor del centenar a partir de la pionera fundación de la Vascongada en 1765. Su objetivo era proveer la educación e instrucción necesarias como base de un desarrollo de la industria popular. En este sentido, puede decirse que las cátedras establecidas por la Vascongada constituyeron una importante excepción. Por lo general, las restantes Sociedades, en su mayoría muy escasas de recursos, volcaron su docencia hacia las matemáticas más básicas y las disciplinas aplicadas, fundamentalmente la agricultura y las artes mecánicas, aunque en algunas se llegó más lejos. En Zaragoza se crearía una cátedra de Matemáticas en 1779, y otras de Botánica y Química en 1797. También en Oviedo se estableció cátedra de Química ${ }^{70}$. En Barcelona, por su parte, la Junta de Comercio, fundada en 1758, desarrolló una importante labor. Estableció una Escuela de Náutica en 1769, una de Dibujo en 1774, y otra de Química en 1804 dotada de su correspondiente laboratorio ${ }^{71}$.

Junto a las enseñanzas promovidas por Sociedades Patrióticas y Juntas de Comercio, el Estado también contribuyó con la dotación de cátedras que, abiertas al público, impartían enseñanzas de índole científica. Tal es el caso de los Laboratorios de Química establecidos en Madrid en los últimos años del siglo. En 1786 se estableció el Laboratorio del Platino y la cátedra de Mineralogía de Indias, y al año siguiente se fundaron otros dos, la Cátedra de Química aplicada a las Artes, dependiente del Ministerio de Hacienda, y el Real Laboratorio de Química, dependiente del de Estado. Estos dos últimos serían refundidos en uno solo en 1799, puesto bajo la dirección de Louis Proust ${ }^{72}$.

\section{Conclusión}

Para terminar, es preciso subrayar la orientación decididamente utilitaria de todas las enseñanzas impartidas en la España del mil setecientos. Se trata de un

70 Véase un panorama de conjunto en J. FERNÁndez PEREZ, "La ciencia ilustrada y las Sociedades Económicas de Amigos del País", en M.A. Sellés et al, Carlos III..., op.cit., págs. 217-232.

71 J. Mones I Pujol-Busquets, Lobra educativa de la Junta de Comerç, Barcelona: Cambra Oficial de Comerç, 1987.

72 Sobre el primero de estos centros, F. ARAGÓN DE LA CRUZ, "Los laboratorios de purificación del platino en Madrid en el siglo XVIII", en M. ESTEBAN PINEIRo et al, (eds.), Estudios..., op. cit., vol. 2, págs. 1005-1012. Para un estudio de conjunto de estos laboratorios, véase R. GAGO, "La ensefianza de la química en Madrid a finales del siglo XVIII", Dynamis, 4 (1984), 
caracteristica que no está desvinculada con las asumidas por el movimiento ilustrado en otros países, pero que en España adquirió un marcado acento. Sus causas son múltiples y difíciles de detallar, pero sin duda hay que contar entre las principales la necesidad siempre presente de modernizar el país y de recuperar en lo posible, frente a Francia e Inglaterra, la perdida posición de preeminencia en el concierto europeo. Otra causa importante puede hallarse en la renuncia a unas especulaciones teóricas que, desde la implantación del Tribunal de la Inquisición, habían sido ajenas a los saberes españoles. La Inquisición, aliada con las fuerzas reaccionarias, siempre estuvo presente a lo largo del siglo y, aunque adormecida, pudo revivir tras la Revolución Francesa para la persecución de unas ideas que tan nefastas habían resultado para la institución monárquica ${ }^{73}$. De modo que siempre se contrapuso la llamada "ciencia útil» a los denominados "sistemas", calificativo bajo el que caían tanto las obras de Descartes como las de Newton. De aquí la preeminencia en los planes de estudio de la física experimental. Y también de aquí, en el fondo, la carencia de una Academia de Ciencias según el modelo francés y el desarrollo de una ciencia española ajena a los debates teóricos y la ausencia, asimismo, de figuras destacadas que realizasen aportaciones al progreso de las disciplinas científicas de carácter especulativo.

págs. 277-300, y también "Cultivo y enseñanza de la química en la España de principios del siglo XIX", en J. M. SÁNCHEZ RON (ed.), Ciencia y sociedad..., op. cit., págs. 129-142, en donde se presenta un panorama global.

73 Cabe recordar aquí los problemas que tuvieron Jorge Juan y Antonio de Ulloa para la publicación de sus Observaciones astronómicas, en las que finalmente se vieron obligados a rubricar de "hipótesis" sus convicciones copernicanas. Si bien Juan, en los años más abiertos que vendrían, podría desquitarse con la publicación del «Estado de la astronomía en Europa, y juicio de los fundamentos sobre que se erigieron los Sistemas del Mundo, para que sirva de guía al método en que debe recibirlos la Nación, sin riesgo de su opinión, y de su religiosidad" (1773). El título, de todos modos, expresa bien la situación del momento. 